\title{
Sustainable malaria control: transdisciplinary approaches for translational applications
}

\author{
Lyn-Marie Birkholtz ${ }^{1}$, Riana Bornman², Walter Focke ${ }^{3}$, Clifford Mutero ${ }^{2,4}$ and Christiaan de Jager ${ }^{2 *}$
}

\begin{abstract}
With the adoption of the Global Malaria Action Plan, several countries are moving from malaria control towards elimination and eradication. However, the sustainability of some of the approaches taken may be questionable. Here, an overview of malaria control and elimination strategies is provided and the sustainability of each in context of vector- and parasite control is assessed. From this, it can be concluded that transdisciplinary approaches are essential for sustained malaria control and elimination in malaria-endemic communities.
\end{abstract}

Keywords: Plasmodium, Anopheles, DDT, Vector control, Anti-malarial drugs

\section{Background}

Malaria is still the most important parasitic disease in humans, caused by Plasmodium spp. parasites that are transmitted through the bite of female Anopheles mosquitoes. Despite recent massive global efforts in malaria control, about $40 \%$ of the world's population in 108 countries still live under the constant risk of malaria infection [1]. The World Health Organization estimates that $\sim 225$ million clinical malaria episodes occur annually and more than $80 \%$ of malaria-associated deaths in the world occur in sub-Saharan Africa [1]. This disease, therefore, rates as one of the major health, socioeconomic and developmental challenges facing many of the world's poorest countries. As a disease of poverty, it forms a major impediment to economic development on the African continent, as it is responsible for the loss of $\sim$ US $\$ 12$ billion of gross domestic product annually. The Millennium Development Goals of the United Nations Development Programme underscore the importance of combating malaria in Target 6C: "to have halted and begun to reverse the incidence of other major diseases by $2015 "$. Malaria is both one of the major disease role players and, in the African context, one of the three major causes of childhood mortality. Thus, clear motivation exists supporting global control of the disease and sustainably eliminating it in areas where transmission has

\footnotetext{
* Correspondence: tiaan.dejager@up.ac.za

${ }^{2}$ University of Pretoria Centre for Sustainable Malaria Control (UP CSMC), University of Pretoria, Private Bag ×323, Pretoria, Gauteng, South Africa 0001 Full list of author information is available at the end of the article
}

been successfully interrupted. Ultimately, the vision of global eradication should drive all current initiatives, investments and decision-making.

A number of international initiatives have been established to coordinate efforts for its control, elimination and, ultimately, eradication. Towards this end, the Global Malaria Action Plan was adopted in 2007, supported by the WHO/Roll Back Malaria Partnership [2] and global funding mechanisms including the Global Fund and the Bill \& Melinda Gates Foundation. Currently, 81 countries are enforcing malaria control while 25 are in pre-elimination and prevention-of-reintroduction phases, with four countries recently being declared malaria free [1]. Under the WHO definition, "malaria elimination" refers to a situation where there is zero local transmission, whereas "eradication" is defined as the permanent zero worldwide incidence of malaria infection [1].

\section{Factors impeding elimination and eradication: sustainability}

Global efforts to eradicate infectious diseases have been successful for smallpox, but in reality, this was due to the simplicity of this organism with visible pathogenesis in patients, which allows very easy monitoring of infectious cases and application of a useful, point-of-care vaccine [3]. However, other major infectious diseases such as poliomyelitis have not been completely eradicated, with several African countries showing an alarming reintroduction of the disease. 
Therefore, if the malaria community is to achieve elimination and eradication, the key realization is that this has to be approached with the long-term goal of sustainability (Figure 1). Several times during our history global efforts have been initiated to control malaria, all with less than satisfactory outcomes (e.g., Global Malaria Eradication Programme, 1955-1969), even though malaria elimination has been achieved in several areas of the world. One of the major realizations from previous malaria-elimination attempts was that, compared to smallpox and poliomyelitis, no single strategy will be applicable for controlling and eliminating malaria. However, to succeed with the current global malaria eradication programme, it has to be understood that, unlike other infectious diseases including smallpox, human immunodeficiency virus infections and tuberculosis, malaria is not caused by a single biological entity. Rather, the disease is the result of a highly complex interplay between three biological systems - including >30 species of Anopheles mosquitoes acting as vectors for the parasite, as well as five species of Plasmodia that infect humans (Plasmodium falciparum; Plasmodium vivax, Plasmodium ovale; Plasmodium malariae; Plasmodium knowlesi), each with its own complex lifecycle, environment, habits and pathogenesis profiles. Additionally, the current global environment conspires in the transmission of malaria with, for instance, travellers' malaria repeatedly reintroducing the disease and global climatic changes forecasting a significant increase in malaria cases. In this context, countries aiming at malaria elimination but which are bordered by countries still experiencing malaria transmission will always be in a situation where their elimination efforts will require strict monitoring and sustained malaria control (Figure 1). Lastly, in countries aiming at zero local transmission, or achieving pre-elimination stages, there will still be a substantial requirement in support of sustained malaria control such that: 1) parasite and vector adaptability is pre-empted; 2) local differences in environment and social structures are taken into consideration; 3) malariarelated health services are maintained in endemic regions; 4) malaria monitoring and case management are continued; 5) continued maintenance of intervention policies will remain imperative; and 6) increased risk of epidemics are monitored (Figure 1).

\section{Sustainable malaria control: what is needed?}

With the classic definition of sustainability implying the ability to maintain an effort at a certain level or rate, sustainable malaria control should, therefore, be seen as longterm effort(s) focused on decreasing malaria-associated fatalities through integrated, creative transdisciplinary approaches that will ultimately contribute to malaria elimination and eradication. Transdisciplinarity in this context requires the combination of basic biomedical sciences and public health efforts and the inclusion of the management of malaria in education and policy making, thereby creating a cross-boundary discipline with a singular focus area. Not only should this lead to translational research with the transfer of knowledge from 'bench-to-bed' but, also, the knowledge from health aspects of malaria control mechanisms should guide and focus research efforts in the basic sciences. The major

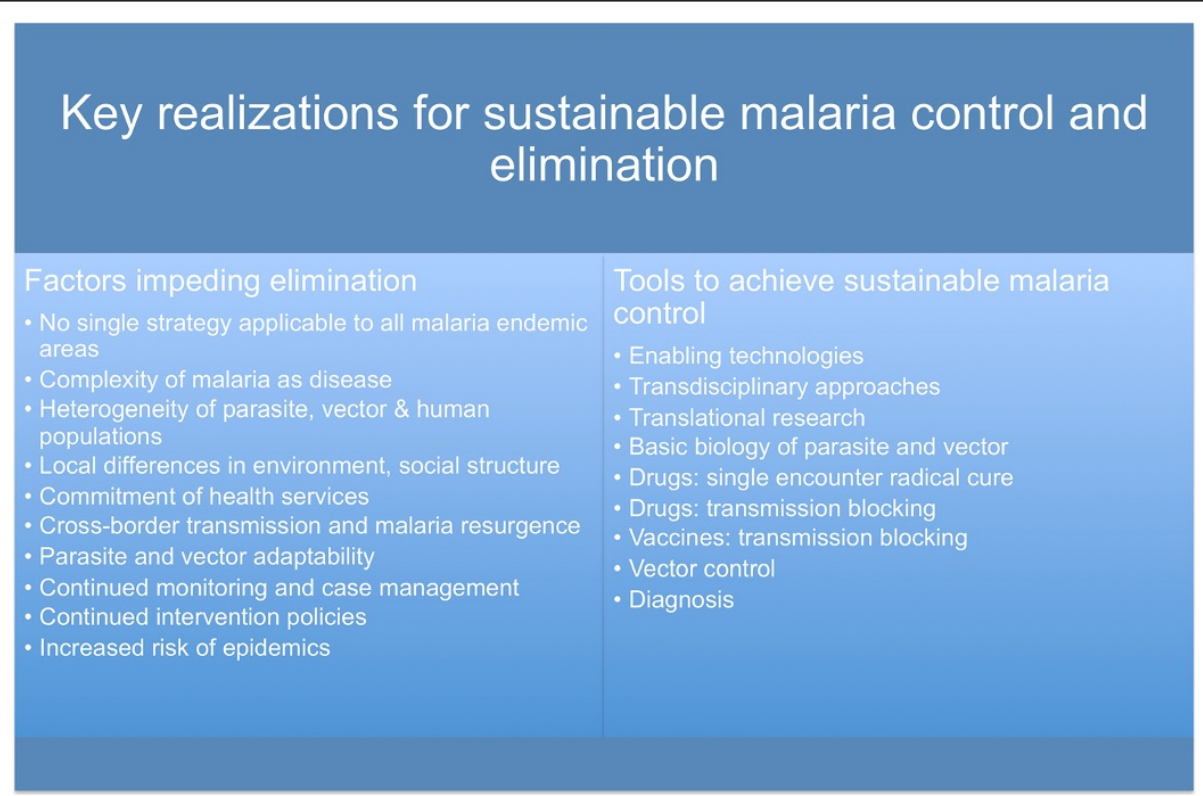

Figure 1 Key realizations impeding and, in contrast, enabling sustainability in malaria control and elimination. 
technical advances that were not available to scientists in the 1950s and 1960s during the previous global malariaeradication attempts should now be exploited, research from the biomedical field should essentially be applied to the field and lastly, and most importantly for sustainable malaria control, major efforts have to be invested in to obtain a clearer understanding of the biology of both the insect vector as well as the parasite itself. In addition, human health aspects of any intervention strategy needs close considerations. Sustained malaria control can be achieved by the use of various physical and biological vector and parasite control strategies aimed at controlling malaria transmission (including drugs, vaccines and innovative vector control strategies), as well as effective tools for malaria diagnosis as well as monitoring and surveillance. The following sections will discuss various aspects of vector and parasite control strategies for controlling malaria transmission, but will not dwell on vaccines or diagnostics, as these are extensively covered elsewhere (e.g. [4,5]).

\section{Vector control strategies and sustainable malaria control}

Vector control is among the key strategies that have significantly contributed to a reduction in malaria illness and deaths in a number of African countries during the last decade [6-9]. The goal of malaria vector control is to reduce vector capacity to below the threshold required to maintain the malaria infection rate. The success so far achieved in malaria vector control has primarily been ascribed to the scaling up of two interventions [6,7]: the use of long-lasting insecticide-treated nets (LLINs or ITNs $[10,11])$ and indoor residual spraying of longlasting insecticides (IRS [12]). The WHO's World Malaria Report (2010) states that by 2015, every person at risk for malaria must have either an ITN or access to IRS [1]. Besides the above, malaria vectors can also be controlled through larval source management using larvicides, i.e. insecticides that specifically target the larval life stage of the mosquito, and biological agents including bacterial larvicides, fungi and larvivorous fish (Table 1
$[13,14])$. Larval source management has been successfully applied as the primary mosquito control method in several US districts, in Canada, Brazil, Singapore and throughout Europe and could be successfully applied in the African context [15]. Additionally, both larval and adult vector populations can be controlled with environmental management [16-19], including permanent infrastructural changes of a capital-intensive nature and creating temporary unfavourable conditions for vector breeding. Without evidence of efficacy of en masse employment of these alternative control strategies, it is at this stage unclear if these will ultimately be sustainable as vector control strategies.

Both primary methods of vector control, LLINs and IRS, rely on the use of long-lasting insecticides recommended for public health use by the WHO (Table 2). Currently, the insecticides most commonly used for LLINs belong to the pyrethroid class while those for IRS are either pyrethroids or members of three other classes: carbamates, organophosphates, and organochlorine insecticides such as dichlorodiphenyltrichloroethane (DDT). Unfortunately, the recent emergence of vector resistance to the most commonly used insecticides undermines the sustainability of recent gains in malaria control. According to a recent WHO report, insecticide resistance has been identified in 64 countries, most of them in sub-Saharan Africa, but also in India [24]. A number of countries continue using DDT as a viable vector control tool, especially in areas of pyrethroid resistance [25,26]. However, the continued dependence on the above-mentioned insecticides for vector control is eminently unsustainable in view of insecticide resistance and potential health and environmental risks.

\section{The effects of vector control strategies on human health}

A growing body of evidence suggests that exposure to DDT and its breakdown product DDE may be associated with adverse health outcomes in humans [34,35]. The following health conditions showed significant associations with DDT or DDE exposure [36]: menstrual cycle

Table 1 Potential sustainability of vector elimination strategies in malaria control, elimination and eradication programmes

\begin{tabular}{|c|c|c|c|}
\hline Subgroup & Advantages & Disadvantages & Sustainability \\
\hline $\begin{array}{l}\text { Aerial spraying } \\
{[20]}\end{array}$ & $\begin{array}{l}\text { Cost-effective and simple } \\
\text { to implement }\end{array}$ & $\begin{array}{l}\text { Only effective for controlling exophilic } \\
\text { mosquitoes }\end{array}$ & $\begin{array}{l}\text { It may fail as it does not target indoor feeding } \\
\text { mosquitoes, which are responsible for the bulk } \\
\text { of malaria transmission }\end{array}$ \\
\hline Larviciding $[21,22]$ & $\begin{array}{l}\text { Can eliminate sources of } \\
\text { mosquitoes }\end{array}$ & $\begin{array}{l}\text { There is need to develop a cheap and effective } \\
\text { larvicide. Insect growth regulators are expensive } \\
\text { and limited in availability. }\end{array}$ & $\begin{array}{l}\text { An. gambiae was eliminated in Brazil using } \\
\text { arsenic larviciding }\end{array}$ \\
\hline $\begin{array}{l}\text { Environmental } \\
\text { control }[16]\end{array}$ & $\begin{array}{l}\text { Can lead to vector } \\
\text { elimination }\end{array}$ & $\begin{array}{l}\text { Environmental modification is expensive and } \\
\text { may be possible only in more advanced economies }\end{array}$ & Potential to bring about vector elimination \\
\hline $\begin{array}{l}\text { Biological control } \\
{[16,23]}\end{array}$ & $\begin{array}{l}\text { Effective if implemented } \\
\text { correctly }\end{array}$ & $\begin{array}{l}\text { Expensive and technically challenging for poorer } \\
\text { countries }\end{array}$ & Potential to bring about vector elimination \\
\hline
\end{tabular}


Table 2 Potential sustainability of transmission blocking strategies in malaria control, elimination and eradication programmes

\begin{tabular}{|c|c|c|c|c|}
\hline & Subgroup & Advantages & Disadvantages & Sustainability \\
\hline \multirow[t]{4}{*}{$\begin{array}{l}\text { Prevention of } \\
\text { mosquito bites }\end{array}$} & ITNs/LLINs $[1,10,11]$ & $\begin{array}{l}\text { Cheap and easy to } \\
\text { implement }\end{array}$ & $\begin{array}{l}\text { Only offers protection during } \\
\text { sleeping time }\end{array}$ & $\begin{array}{l}\text { Mosquitoes can still transmit malaria } \\
\text { before sleeping time }\end{array}$ \\
\hline & Repellents [27] & Effective in preventing bites & $\begin{array}{l}\text { Short residual efficacy, } \\
\text { strong smell, irritating to } \\
\text { the skin }\end{array}$ & $\begin{array}{l}\text { Does not reduce vector populations; } \\
\text { mosquitoes will simply migrate to } \\
\text { areas where repellents are not in use }\end{array}$ \\
\hline & Attractants [28] & $\begin{array}{l}\text { Safe for humans and } \\
\text { environment, cheap }\end{array}$ & $\begin{array}{l}\text { Chemicals that attract } \\
\text { have not been fully isolated }\end{array}$ & Very promising technique \\
\hline & House design [29] & Very effective and cheap & $\begin{array}{l}\text { Closing up eaves increases } \\
\text { indoor temperatures }\end{array}$ & $\begin{array}{l}\text { Does not reduce vector populations, but } \\
\text { worked well for Europe and North America }\end{array}$ \\
\hline \multirow{3}{*}{$\begin{array}{l}\text { Killing of } \\
\text { mosquitoes } \\
\text { after they } \\
\text { have bitten }\end{array}$} & IRS $[1,12]$ & Breaks transmission cycle & $\begin{array}{l}\text { Too much reliance on DDT; } \\
\text { dusting of sprayed insecticides } \\
\text { a problem, labour-intensive }\end{array}$ & $\begin{array}{l}\text { Residual efficacy limited to at most one } \\
\text { season }\end{array}$ \\
\hline & ITWL $[30,31]$ & $\begin{array}{l}\text { Similar to IRS but eliminates } \\
\text { dusting and short residual } \\
\text { efficacy of insecticides }\end{array}$ & $\begin{array}{l}\text { User acceptability may be a } \\
\text { challenge }\end{array}$ & $\begin{array}{l}\text { Emerging polymer technology will } \\
\text { eliminate the need to spray chemicals }\end{array}$ \\
\hline & $\begin{array}{l}\text { IRS/ITWL with } \\
\text { natural insecticides } \\
{[32,33]}\end{array}$ & Low mammalian toxicity & Short residual efficacy & Pyrethrin is the most effective insecticide \\
\hline
\end{tabular}

alterations [37,38]; foetal loss in women in countries with recent usage of DDT [39,40]; reduced gestational age and increased rates of preterm birth [41]; breast cancer pre-pubertal exposure (prior to age 14, not later) [42]; testicular cancer prospective exposure measure-provided evidence [43]; liver cancer [44]; reduced childhood or pubertal growth after prenatal or early life exposures to DDE [45]; DNA damage and apoptosis [46] and impaired neurodevelopment up to age four $[47,48]$. Eskenazi et al. [35] described growing evidence that DDT exposures may be associated with adverse health outcomes for breast cancer, diabetes, decreased semen quality, spontaneous abortion, and impaired neurodevelopment in children. Higher rates of urogenital malformations in newborn boys of mothers who live in DDT-treated areas have also been reported, although a quantitative human health risk assessment could not be performed [49].

However, for several other health conditions, the effects of DDT or DDE are inconclusive or the data insufficient to draw clear conclusions. These include: exposure to DDT during lactation; influence of exposure on age or menarche or pubertal stages; time to pregnancy as an indicator of fertility or fecundity; thyroid hormones; lung/pancreatic/endometrial or prostate cancers; nonHodgkin's lympohoma; diabetogenic effects; immunotoxicity; cryptorchidims; and anogentical distance or hypospadias. Additionally, no significant associations with DDT or DDE were demonstrated for foetal growth restriction, cancer incidence or mortality, including breast cancer at the time of diagnosis or during adulthood [36]. Owing to these inconclusive and conflicting datasets, DDT use is approved by the WHO.
Pyrethroid insecticides are often used as an alternative to DDT in IRS programmes, especially deltamethrin [26]. However, animal studies suggest that prenatal exposure to pyrethroids may also adversely affect neurodevelopment and this raises concern for people living in malarial areas where IRS is conducted with both chemicals [36]. Additionally, pyrethroids are often used for agricultural purposes and domestic pest control, which may further increase total pyrethroid exposure and increase instances of pyrethroid resistance developing and impeding sustainable use of this insecticide.

In general, there are many instances where the data on health effects of insecticide usage are inconclusive and consequently adverse health effects in the currently exposed populations or their offspring (via epigenetic mechanisms) cannot be ruled out. Information on exposures to children living in IRS communities is virtually non-existent and research has to focus on both foetal and neonatal exposures to determine the long-term safe use of these chemicals related to IRS. Filling those gaps in high-quality data on risks to humans challenges scientists to use opportunities in currently exposed populations to draw scientifically justifiable conclusions. Since there is a growing societal awareness about health and the environment, uncertainties about current strategies will eventually only limit long-term sustainability.

\section{Sustainable and alternative vector control strategies}

It is estimated that existing malaria vector control interventions can only reduce the annual inoculation rate by an order of magnitude [50]. This suggests that the interventions currently recommended by the WHO may not 
be sufficient to achieve malaria elimination in Africa. There is therefore a need for effective vector control interventions that can deal a "knockout blow" to malaria vectors in a sustainable manner.

\section{Integrated vector management}

Integrated vector management (IVM) could be seen as a key strategy for sustainable malaria vector control and as a rational decision about the optimal use of resources for vector control [51-53]. IVM aims to improve the efficacy, cost effectiveness, ecological soundness and sustainability of vector control to prevent or interrupt disease transmission [54] by using a range of control options that can respond better to the natural variation and heterogeneity of vector populations [55]. The key elements of IVM can be summarized as: 1) effective targeting of different vector species and developmental stages of vectors in a given geographical area; 2) combining of chemical- and non-chemical methods in order to arrest the development of insecticide resistance in vector populations and minimize the negative health and environmental impacts of chemicals [51,54]; 3) intersectoral collaborations between health and agricultural sectors, for example, for effective implementation of IVM; and 4) development of the requisite human resources, including the training of a cadre of IVM practitioners in entomological and program management skills.

Behavioural and ecological variations in mosquito vectors are readily evident in relation to the day-time resting behaviour of fed adult mosquitoes of the Anopheles gambiae species complex (= Anopheles gambiae sensu lato [s.1.]) and Anopheles funestus [56] found in Africa. Anopheles gambiae s.s and An. funestus rest almost exclusively indoors under natural conditions and feed exclusively on human hosts. In contrast, Anopheles arabiensis normally rests either indoors or outdoors in a variety of micro-habitats such as ground pits and feeds either indoors or outdoors on human hosts or domestic animals [57]. It is therefore obvious that interventions aimed at the various species need to take different behavioural variability into account to be fully effective. On the one hand, the control of An. gambiae s.s and $A n$. funestus can be achieved by largely targeting the adult mosquitoes indoors, since this is where they normally feed and rest before leaving houses in search of oviposition sites. However, continuous use of insecticides indoors to target An. gambiae s.s and An. funestus is now known to change the behaviour of certain vector populations such that these vectors end up feeding and resting more frequently outdoors than indoors or start to bite early in the evenings before people sleep under the protection of bed nets [58].

IVM additionally underscores the combination of chemical and non-chemical methods in order to arrest the development of insecticide resistance in vector populations and minimize the negative health and environmental impacts of chemicals [51,54]. Non-chemical methods including the use of bio-larvicides (Table 1) and environmental management may prove as successful as chemical means and be applicable to sustainable programmes. Environmental management for both vector and larvae control includes closely related strategies namely environmental modification (e.g. infrastructural changes) and environmental manipulation (e g achieving unfavourable conditions for vector breeding including ditch filling, stream flushing etc.). IVM contributes towards sustainable malaria control by mitigating and managing insecticide resistance through ensuring no over-reliance on a particular insecticide for a prolonged period of time or rotating different classes of insecticides. Environmental management of potential mosquito breeding habitats can also serve as a practical alternative, or a complementary intervention for eliminating the malaria vector problem, in areas where LLINs and IRS have been rendered ineffective by resistance.

Collaboration between the health sector and other sectors is an essential element of implementation of IVM, since activities and policies outside of the health sector can have important implications for malaria control. For example, conflicting agendas may exist between government agencies where a department of health may advocate the use of insecticides but a department of environmental affairs will spearhead national implementation plans for phasing out that exact chemical. Independent evidence-based research is, therefore, imperative for providing information related to the potential benefits and risks of controlling malaria. Moreover, the use of agricultural pesticides to protect crops from pest attack is known to lead to insecticide resistance in vectors, thus rendering interventions such as IRS and LLINs ineffective in the areas where such a problem exists $[59,60]$. By promoting cross-sectoral collaboration between the ministries of health and agriculture, it would be possible to minimize agriculture-associated malaria risks.

Programmatic control of malaria vectors requires that policy decisions regarding the vector control strategy, as well as the specific interventions, are made on the basis of a sound understanding of the behaviour, ecology and population dynamics of the local vector species [61]. The relevant basic and operational research therefore needs to be conducted in order to effectively target the specific vector. Such research should also facilitate the mapping of the spatial and seasonal variation in malaria-transmission risks in different geographic locations. Systematic entomological surveillance is also crucial for monitoring and evaluating the success or limitations of the different interventions being used. Research is, therefore, a key element of IVM as the means for generating 
the evidence base needed to guide vector control interventions within an IVM context in certain African countries.

\section{Prevention of mosquito bites and killing mosquitoes after they have bitten}

Interventions falling in these two categories and preventing transmission from vector to host are presented in Table 2. Mosquito control by suitable house designs, that prevent mosquitoes from entering, was extensively used before the advent of DDT and pyrethroids and apparently proved to be effective [29]. Mosquito control in Europe and North America was achieved largely through suitable house design, which can significantly reduce the number of mosquitoes feeding indoors by up to $80 \%$ [29]. Additionally, successful attempts have been made to divert mosquitoes away from humans, using attractants and repellents. The attractants seem to work by inhibiting $\mathrm{CO}_{2}$ receptors or continuously activating $\mathrm{CO}_{2}$ sensors, or by simulating the smell of $\mathrm{CO}_{2}$, thus curtailing the ability of a mosquito to locate a victim using $\mathrm{CO}_{2}$ sensory neurons [28]. The use of repellents has also been shown to be effective in preventing bites from mosquitoes, of which DEET ( $N, N$-diethyl-m-toluamide) is currently the most effective and most widely used repellent. DEET repels by blocking the lactic acid receptors in mosquitoes, resulting in the insect losing the trail leading to the host [27].

Larviciding, environmental management, genetic manipulation, attractants and ITWL all offer promising vector control techniques for the future. However, larviciding requires expensive applications; environmental management would require government commitment to infrastructural management; and genetic manipulation would be expensive over a sustained period of implementation and also technically challenging for poor African countries. Alternatively, durable insecticide-treated wall linings (ITWLs), a recent product concept that combines aspects of LLINs and IRS, promise long-lasting residual efficacy, negating the need for repeated annual wall treatments as currently occurs with IRS. In combination with newly identified suitable insecticide alternatives using slow-release formulations [62,63], ITWL can be used as a substitute for IRS, since it allows protective containment of the insecticide in a polymer, resulting in a longer residual efficacy. Additionally, natural insecticides including permethrin or pyrethrin and essential oils such as thymoquinone, nootkatone and carvacol [32] should be explored if their residual period of use could be increased [33].

\section{Sustainable parasite control}

Although there are alternatives to insecticides for vector control, parasite control is still fully reliant on anti-malarial drugs, both for prophylactic use and for treatment of the disease. The addition of a vaccine to the anti-malarial weaponry will enable long-term protection that cannot be achieved by chemical interventions, but it is unlikely that either a vaccine on its own or control of the parasite on its own will ever be effective for sustainable malaria control, which necessitates vigilant coordination of the available control strategies. This is particularly true if malaria eradication is to be achieved by reducing parasite numbers to prevent parasite transmission. However, malaria control is fragile and current control programmes are threatened by various factors, the most alarming of which is the rapid development of drug- and insecticide-resistant forms of the malaria parasite and the mosquito vector, respectively. This is particularly significant for P. falciparum parasites, which have to various degrees developed resistance against all currently used anti-malarials.

The parasite has an extremely complex life cycle, with sexual development in the mosquito vector and asexual replication in the human host's erythrocytes (Figure 2). During the latter, the parasite is massively replicated reaching numbers in the billions. This makes effective targeting of this replication cycle almost impossible, as is evident from rapid evolvement of drug-resistant forms. Fortuitously, there are points in the parasite's development where population bottlenecks exist, and this is particularly when the parasite resides in the mosquito vector or when 100 to 1,000 parasites are transmitted between humans and mosquitoes (Figure 2).

Various partnerships and consortia (e.g., Medicines for Malaria Venture [64,65]; CRIMALDDI [66]; and malERA [67]) emphasize the need for novel anti-malarials that are: 1) effective against erythrocytic stages and exoerythrocytic stages of the parasite; 2) effective against resistant forms of the parasite; 3 ) chemically distinct and with new mechanisms of action; 4) safe without associated toxicities; 5) pharmacokinetically amenable to once-daily oral dosing; and 6) economically viable. Target product profiles for anti-malarials that meet these criteria and support the malaria-elimination strategy are have been identified and are broadly grouped into three areas: 1) control of the disease (treatment of infected patients); 2) blocking the transmission cycle; and 3) radical cures for malaria (e. g., targeting $P$. vivax hypnozoites in the livers of infected patients) $[65,67]$.

Almost all currently used anti-malarials target various processes in the asexual, erythrocytic cycle with mostly unknown modes-of-action - including antibiotics (ciprofloxasin, doxycyclin, fosmidomycin, rifampicin), antifolates (pyrimethamine, proguanil and sulphadoxine), chloroquine and quinolone derivatives (amodiaquine, mefloquine), artemisinins and atovaquone. As the replication of the parasite in erythrocytes is responsible for malaria pathogenesis and death, parasite development in the erythrocytic cycle will always need to be one of the major focus areas for 


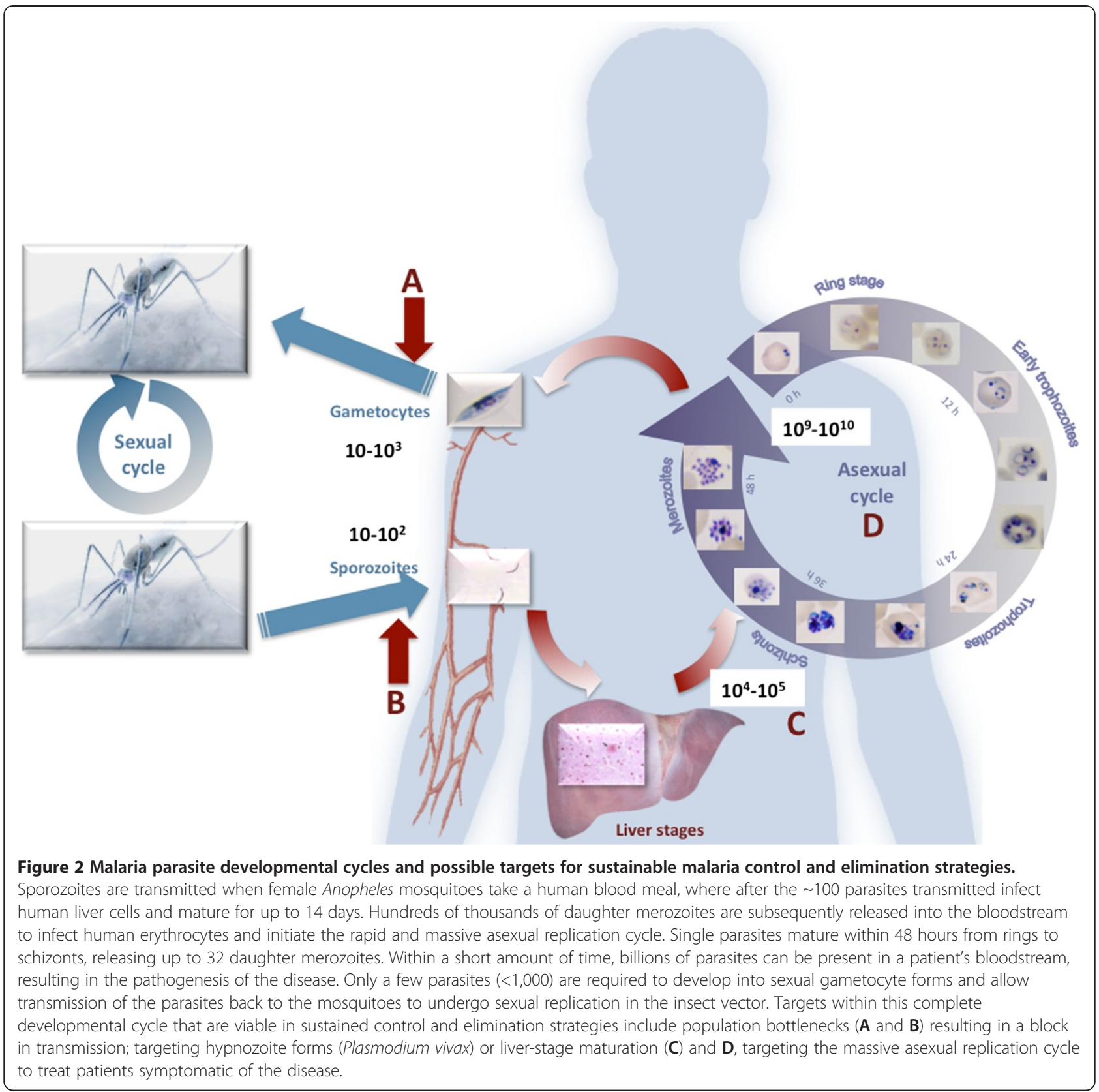

development of anti-malarial against novel targets to sustain malaria control strategies (Figure 2, Table 3). Therefore, research into new drugs and novel drug targets is still and will remain imperative and the useful lifetime of current anti-malarials (including artemisinin combination therapies) has to be maximized. Any new drug targeting the erythrocytic cycle will have to show a rate of killing comparative to its half-life [68] and at drug concentrations $<10 \mathrm{nM}$ in vitro. Pre-clinical candidates have to show good pharmacokinetic parameters including good oral bioavailability to be applicable in the field in malaria-endemic regions, especially also for children. Several new candidate drugs/drug targets are under investigation, including for example targeting dihydroorotate dehydrogenase [69] and the mitochondrial $\mathrm{BC} 1$ complex (atovaquone derivatives) [70]. High-throughput screening of libraries of $\sim 4$ million chemical entities (e.g. from Glaxo-SmithKlein, Novartis and St. Jude's Childrens Hospital), have resulted in $\sim 20000$ compounds with $<1 \mu \mathrm{M}$ activity against asexual-stage malaria parasites in vitro, which promises to be a invaluable resource in anti-malarial discovery programmes.

Sustainable malaria control with chemotherapeuticals additionally requires targeting exo-erythrocytic and transmission-causing forms of the parasite (Figure 2, 
Table 3 Potential sustainability of parasite control strategies in malaria control, elimination and eradication programmes [64-67]

\begin{tabular}{|c|c|c|c|}
\hline Subgroup & Advantages & Disadvantages & Sustainability \\
\hline $\begin{array}{l}\text { Chemoprophylaxis: } \\
\text { asexual stages }\end{array}$ & Fast acting, prevents onset of infection and disease & Resistance developed & $\begin{array}{l}\text { No, not if only targeting } \\
\text { prevention of infection }\end{array}$ \\
\hline $\begin{array}{l}\text { Chemoprophylaxis: } \\
\text { transmission blocking }\end{array}$ & $\begin{array}{l}\text { Sporozoite stages and hepatocytic stages targeted, could } \\
\text { have simultaneous prevention of onset of disease }\end{array}$ & $\begin{array}{l}\text { Drug delivery and } \\
\text { technical constraints }\end{array}$ & Yes \\
\hline $\begin{array}{l}\text { Chemotherapy: } \\
\text { treatment of disease }\end{array}$ & $\begin{array}{l}\text { Decrease parasite burden, treat malaria-associated } \\
\text { symptoms }\end{array}$ & $\begin{array}{l}\text { Resistance developed, } \\
\text { new drugs and targets } \\
\text { needed }\end{array}$ & $\begin{array}{l}\text { Maybe, if drugs block erythrocytic } \\
\text { development as well as formation } \\
\text { of gametocytes }\end{array}$ \\
\hline $\begin{array}{l}\text { Chemotherapy: } \\
\text { antihypnozoite }\end{array}$ & Treatment of P. vivax liver stage malaria & $\begin{array}{l}\text { Technical constraints in } \\
\text { drug development }\end{array}$ & $\begin{array}{l}\text { Maybe, species specific } \\
\text { eliminations }\end{array}$ \\
\hline $\begin{array}{l}\text { Chemotherapy: } \\
\text { transmission blocking }\end{array}$ & $\begin{array}{l}\text { Block human-mosquito transmission (gametocytocidal), } \\
\text { could have simultaneous prevention of onset of disease }\end{array}$ & $\begin{array}{l}\text { Technical constraints in } \\
\text { drug development }\end{array}$ & Yes \\
\hline
\end{tabular}

Table 3), especially dormant liver-stage infection with $P$. vivax hypnozoites, particularly in countries where P. vivax infection is rampant [71]. Only a single drug, primaquine, effectively targets hypnozoites and drugdiscovery programs in this field are limited due to technical constraints in culturing liver-stage parasites of $P$. vivax and other Plasmodium species. Such an in vitro culturing ability will enable downstream developments of diagnostics methods and novel drugs. Several initiatives include 3D culture scaffolds for liver cell culturing [72] but require transdisciplinary approaches between material scientists, cell biologists and parasitologists.

One of the areas that could have the biggest impact in sustainable malaria control and malaria elimination is interruption of the transmission of the parasite between humans and mosquito vectors (Figure 2). The value of transmission-blocking drugs that target population bottlenecks in the parasite's life cycle lies in the ability to target the parasite both in the host (gametocytes) as well as in the mosquito (sporozoites). Currently used but compromised anti-malarials, such as artemisinin and primaquine, already target some stages of gametocyte development, illustrating the potential of such an approach. Additionally, drugs targeting both asexual and sexual forms of the parasite would further enhance the value of such drugs [73]. However, gametocytocidal drugs could always be used in combination with drugs targeting asexual parasites, if comparative pharmacokinetic properties could be ensured. Novel methods for screening of compounds with gametocytocidal activity are available [74,75]. However, development of transmission blocking drugs requires transdisciplinary approaches of combining expertise from parasite biologists, medicinal chemists, human physiologists and entomologists with the advantage that the complete life cycle of the parasite from mosquitoes to human hosts [75] can be investigated to determine the efficacy of transmission-blocking interventions. This will allow early detection of unanticipated factors influencing a positive outcome - for example, parasite-resistance development, human host influences, etc.

One important constraints of the current anti-malarial arsenal is their limited chemical scaffolds, apparently similar modes-of-action and thus increased probability of developing shared mechanisms of resistance. Focused efforts on identifying chemically distinct compounds with proven novel modes-of-action is required to maintain a steady stream of new anti-malarials. Such an approach necessitates identification of parasite-specific processes that are clearly distinct from those of the human host and essential to parasite survival. Surprisingly little is known about basic biological processes governing the parasite's pathogenesis. However, exploitation of the immense datasets resulting from functional genomics investigations of the parasite has not met the initial expectations, mostly due to a lack of understanding of specific processes in the parasite. This poses a major obstacle in devising new anti-malarial control tools for sustainable malaria control.

\section{Conclusions}

Despite many of the challenges facing malaria control programmes, several countries have been able to achieve malaria elimination. Countries currently at malaria control and pre-elimination stages need to be vigilant and systematic in their pursuit of elimination to ensure sustainability. Continued funding by governments of malaria-endemic regions is imperative to further sustain and progress malaria control and elimination programmes. Moreover, the international community has to invest heavily in novel research and development agendas if the ultimate aim of malaria eradication is to be achieved.

Transdisciplinary approaches are essential in order to sustain control and elimination of this complex disease. Specific focus areas under the auspices of both vector and parasite control must include consideration of the impact of control measures on human health of the affected communities (Figure 3). In the context of 


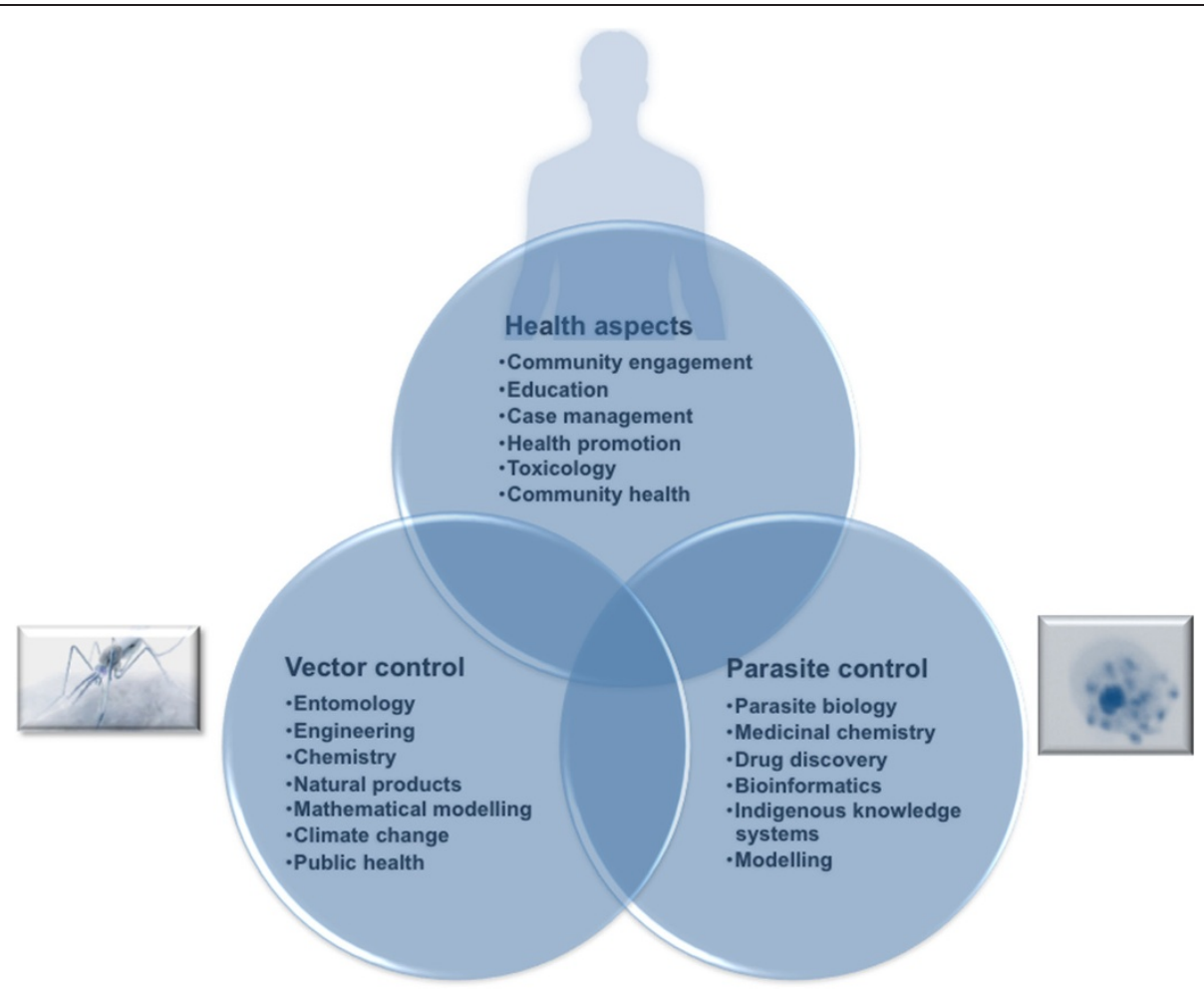

Figure 3 Transdisciplinary approaches to enable sustained malaria control and elimination, allowing translational applications to the malaria community.

parasite control, transdisciplinary initiatives combining expertise from parasite biology, medicinal chemistry, drug discovery, mathematical modelling and bioinformaticsbased data mining and predictions, and indigenous knowledge systems provide opportunities to streamline the sustained pipeline of novel chemical entities that target weak points in the parasite's biology. Vector control strategies are highly reliant on transdisciplinary approaches, as depicted by IVM. Thus, transdisciplinary measures include those that appear to contribute to six key elements of IVM: 1) integrated approaches requiring entomology, chemistry, biochemistry, engineering and environmental health; 2) inter-sectoral collaborations including health, agriculture, environment and planning sectors; 3) evidence-based decision making requiring entomologists, parasitologists, epidemiology, medicine and policy research; 4) Advocacy and social mobilization within social and political sciences and community health; 5) legislation within public health and environmental law and 6) capacity-building between e.g. social sciences and health education etc. Additionally, collaborations between vector biologists, entomologists, engineers, chemists, natural product specialists, mathematical modelling, climate change specialists and public health researchers would further strengthen such programmes. Community involvement, education and sustained malaria case management are essential for any application of transdisciplinary vector control programmes.

The successful integration of these transdisciplinary research approaches therefore holds immense promise for translationary applications, especially if they can originate in malaria-endemic countries in Africa that will lead to benefitting malaria-endemic communities and further ensures sustained malaria control and elimination.

\section{Abbreviations}

DDT: Dichlorodiphenyltrichloroethane; DDE: Dichlorodiphenyldichloroethylene; IRS: Indoor residual spraying; ITN: Insecticide-treated net; ITWLS: Insecticide-treated wall linings; IVM: Integrated vector management; WHO: World Health Organization.

\section{Competing interests}

The authors declare that they have no competing interests.

\section{Authors' contributions}

LMB conceived the idea for the manuscript, wrote the section on parasite control and overall manuscript preparation; RB: the section on adverse health aspects of vector control; WF: vector control strategies; CM: vector control strategies and integrated vector management; CdJ: overall manuscript preparation. All authors read and approved the final manuscript.

\section{Acknowledgements}

We thank Abraham I Louw for careful reading of the manuscript. All authors are supported by the University of Pretoria as members of the University of Pretoria Centre for Sustainable Malaria Control (www.malaria.up.ac.za). 


\section{Author details}

'Department of Biochemistry, University of Pretoria, Private Bag x20, Pretoria, Gauteng, South Africa 0028. '2University of Pretoria Centre for Sustainable Malaria Control (UP CSMC), University of Pretoria, Private Bag x323, Pretoria, Gauteng, South Africa 0001. ${ }^{3}$ Department of Chemical Engineering, University of Pretoria, Private Bag x20, Pretoria, Gauteng, South Africa 0028. ${ }^{4}$ International Centre of Insect Physiology and Ecology, P.O. Box 30772, Nairobi, Kenya 00100.

Received: 30 October 2012 Accepted: 14 December 2012

Published: 26 December 2012

\section{References}

1. WHO: World Malaria Report. Geneva: World Health Organization; 2010.

2. RBM: The Global Malaria Action Plan: For a malaria-free world. Geneva: Roll Back Malaria Partnership; 2008.

3. Breman JG, de Quadros CA, Dowdle WR, Foege WH, Henderson DA, John TJ, Levine MM: The role of research in viral disease eradication and elimination programs: lessons for malaria eradication. PLoS Med 2011, 8:e1000405.

4. MalERA: A research agenda for malaria eradication: vaccines. PLOS Med 2011, 8:e1000398.

5. MalERA: A research agenda for malaria eradication: diagnoses and diagnostics. PLoS Med 2011, 8:e1000396.

6. Kokwaro G: Ongoing challenges in the management of malaria. Malar $J$ 2009, 8 Suppl 1:S2

7. Raghavendra K, Barik TK, Reddy BP, Sharma P, Dash AP: Malaria vector control: from past to future. Parasitol Res 2011, 108:757-779.

8. WHO: Malaria vector control and personal protection. Geneva: World Health Organization; 2006

9. RBM: Key facts, figures and strategies: The global malaria action plan. Geneva: Roll Back Malaria Partnership; 2008.

10. Lengeler C: Insecticide-treated bed nets and curtains for preventing malaria. Cochrane Database Syst Rev 2004, 2:CD000363.

11. Okumu FO, Moore SJ: Combining indoor residual spraying and insecticidetreated nets for malaria control in Africa: a review of possible outcomes and an outline of suggestions for the future. Malar J 2011, 10:208.

12. Pluess B, Tanser FC, Lengeler C, Sharp BL: Indoor residual spraying for preventing malaria. Cochrane Database Syst Rev 2010, 4:CD006657.

13. WHO: Vector control for malaria and other mosquito-borne diseases. Geneva: World Health Organization; 1995.

14. USAID: Integrated vector management programs for malaria vector control: Programmatic environmental assessment. Washington, DC: United States Agency for International Development; 2011.

15. Fillinger $U$, Lindsay SW: Larval source management for malaria control in Africa: myths and reality. Malar J 2011, 10:353.

16. Keiser J, Singer $\mathrm{BH}$, Utzinger J: Reducing the burden of malaria in different eco-epidemiological settings with environmental management: a systematic review. Lancet Infect Dis 2005, 5:695-708.

17. WHO: Manual on environmental management fo rmosquito control: with special emphasis on malaria vectors. Geneva: World Health Organization; 1982.

18. WHO: WHO study group on vector control for malaira and other mosquito-borne disease. Geneva: World Health Organization; 1995.

19. Rozendaal JA: Vector control: methods for use by individuals and communities. Geneva: World Health Organization; 1997.

20. Mount GA, Biery TL, Haile DG: A review of ultralow-volume aerial sprays of insecticide for mosquito control. J Am Mosq Control Assoc 1996, 12:601-618.

21. Walker K, Lynch M: Contributions of Anopheles larval control to malaria suppression in tropical Africa: review of achievements and potential. Med Vet Entomol 2007, 21:2-21.

22. Mittal PK: Biolarvicides in vector control: challenges and prospects. J Vector Borne Dis 2003, 40:20-32.

23. Blaustein L: Larvivorous fishes fail to control mosquitoes in experimental rice plots. Hydrobiologica 1992, 232:219-232

24. WHO: Global plan for insecticide resistance management in malaria vectors. Geneva: World Health Organization; 2012.

25. Hargreaves K, Koekemoer LL, Brooke BD, Hunt RH, Mthembu J, Coetzee M: Anopheles funestus resistant to pyrethroid insecticides in South Africa. Med Vet Entomol 2000, 14:181-189.
26. Moonasar D, Nutulaganti T, Kruger PS, Mabuza A, Raswiswi ES, Benson FG, Maharaj R: Malaria control in South Africa 2000-2010: beyond MDG6. Malar J 2012, 11:294

27. Davis EE: A receptor sensitive to oviposition site attractants on the antennae of the mosquito. Aedes Aegypti. J Insect Physiol 1976, 22:13711376.

28. Stopfer M: Malaria: Mosquitoes bamboozled. Nature 2011, 474:40-41.

29. Lindsay SW, Emerson PM, Charlwood JD: Reducing malaria by mosquitoproofing houses. Trends Parasitol 2002, 18:510-514.

30. Pulford J, Tandrapah A, Atkinson JA, Kaupa B, Russell T, Hetzel MW: Feasibility and acceptability of insecticide-treated plastic sheeting (ITPS) for vector control in Papua New Guinea. Malar J 2012, 11:342.

31. Messenger LA, Matias A, Manana AN, Stiles-Ocran JB, Knowles S, Boakye DA, Coulibaly MB, Larsen ML, Traore AS, Diallo B, Konate M, Guindo A, Traore SF, Mulder CE, Le H, Kleinschmidt I, Rowland M: Multicentre studies of insecticide-treated durable wall lining in Africa and South-East Asia: entomological efficacy and household acceptability during one year of field use. Malar J 2012, 11:358.

32. McAllister JC, Adams MF: Mode of action for natural products isolated from essential oils of two trees is different from available mosquito adulticides. J Med Entomol 2010, 47:1123-1126.

33. Schmutterer $\mathrm{H}$ : Potential of azadirachtin-containing pesticides for integrated pest control in developing and industrialised countries. J Insect Physiol 1988, 4:713-719.

34. Rogan WJ, Chen A: Health risks and benefits of bis(4-chlorophenyl)-1, 1,1-trichloroethane (DDT). Lancet 2005, 366:763-773.

35. Eskenazi B, Chevrier J, Rosas LG, Anderson HA, Bornman MS, Bouwman H, Chen A, Cohn BA, de Jager C, Henshel DS, Leipzig F, Leipzig JS, Lorenz EC, Snedeker SM, Stapleton D: The Pine River statement: human health consequences of DDT use. Environ Health Perspect 2009, 117:1359-1367.

36. WHO: DDT in indoor residual spraying: human health aspects. Geneva: World Health Organization; 2011.

37. Windham GC, Lee D, Mitchell P, Anderson M, Petreas M, Lasley B: Exposure to organochlorine compounds and effects on ovarian function. Epidemiology 2005, 16:182-190.

38. Perry MJ, Ouyang F, Korrick SA, Venners SA, Chen C, Xu X, Lasley BL, Wang $X: A$ prospective study of serum DDT and progesterone and estrogen levels across the menstrual cycle in nulliparous women of reproductive age. Am J Epidemiol 2006, 164:1056-1064.

39. Venners SA, Korrick S, Xu X, Chen C, Guang W, Huang A, Altshul L, Perry M, Fu L, Wang X: Preconception serum DDT and pregnancy loss: a prospective study using a biomarker of pregnancy. Am J Epidemio/ 2005 162:709-716.

40. Longnecker MP, Klebanoff MA, Dunson DB, Guo X, Chen Z, Zhou H, Brock JW: Maternal serum level of the DDT metabolite DDE in relation to fetal loss in previous pregnancies. Environ Res 2005, 97:127-133.

41. Longnecker MP, Klebanoff MA, Zhou H, Brock JW: Association between maternal serum concentration of the DDT metabolite DDE and preterm and small-for-gestational-age babies at birth. Lancet 2001, 358:110-114.

42. Cohn BA, Wolff MS, Cirillo PM, Sholtz Rl: DDT and breast cancer in young women: new data on the significance of age at exposure. Environ Health Perspect 2007, 115:1406-1414

43. McGlynn KA, Quraishi SM, Graubard BI, Weber JP, Rubertone MV, Erickson RL: Persistent organochlorine pesticides and risk of testicular germ cell tumors. J Natl Cancer Inst 2008, 100:663-671.

44. McGlynn KA, Abnet CC, Zhang M, Sun XD, Fan JH, O'Brien TR, Wei WQ, Ortiz-Conde BA, Dawsey SM, Weber JP, Taylor PR, Katki H, Mark SD, Qiao YL: Serum concentrations of 1,1,1-trichloro-2,2-bis(p-chlorophenyl)ethane (DDT) and 1,1-dichloro-2,2-bis(p-chlorophenyl)ethylene (DDE) and risk of primary liver cancer. J Natl Cancer Inst 2006, 98:1005-1010

45. Karmaus W, Asakevich S, Indurkhya A, Witten J, Kruse H: Childhood growth and exposure to dichlorodiphenyl dichloroethene and polychlorinated biphenyls. J Pediatr 2002, 140:33-39.

46. Perez-Maldonado IN, Athanasiadou M, Yanez L, Gonzalez-Amaro R, Bergman A, Diaz-Barriga F: DDE-induced apoptosis in children exposed to the DDT metabolite. Sci Total Environ 2006, 370:343-351.

47. Eskenazi B, Marks AR, Bradman A, Fenster L, Johnson C, Barr DB, Jewell NP. In utero exposure to dichlorodiphenyltrichloroethane (DDT) and dichlorodiphenyldichloroethylene (DDE) and neurodevelopment among young Mexican American children. Pediatrics 2006, 118:233-241. 
48. Ribas-Fito N, Torrent M, Carrizo D, Munoz-Ortiz L, Julvez J, Grimalt JO, Sunyer J: In utero exposure to background concentrations of DDT and cognitive functioning among preschoolers. Am J Epidemiol 2006, 164:955-962.

49. Bornman R, de Jager C, Worku Z, Farias P, Reif S: DDT and urogenital malformations in newborn boys in a malarial area. BJU Int 2010, 106:405-411.

50. MalERA: A research agenda for malaria eradication: vector control. PLOS Med 2011, 8:e1000401.

51. WHO: Global strategic framework for integrated vector management. Geneva: World Health Organization; 2004.

52. WHO: WHO position statement on integrated vector management. Geneva: World Health Organization; 2008.

53. Townson $H$, Nathan MB, Zaim M, Guillet $P$, Manga L, Bos R, Kindhauser M: Exploiting the potential of vector control for disease prevention. Bull World Health Organ 2005, 83:942-947.

54. Beier JC, Keating J, Githure JI, Macdonald MB, Impoinvil DE, Novak RJ: Integrated vector management for malaria control. Malar J 2008, 7 Suppl 1:S4.

55. Mutero CM, Schlodder D, Kabatereine N, Kramer R: Integrated vector management for malaria control in Uganda: knowledge, perceptions and policy development. Malar J 2012, 11:21.

56. White GB: Anopheles gambiae complex and disease transmission in Africa. Trans R Soc Trop Med Hyg 1974, 68:278-301.

57. Derua YA, Alifrangis M, Hosea KM, Meyrowitsch DW, Magesa SM, Pedersen EM, Simonsen PE: Change in composition of the Anopheles gambiae complex and its possible implications for the transmission of malaria and lymphatic filariasis in north-eastern Tanzania. Malar J 2012, 11:188.

58. Bradley J, Matias A, Schwabe C, Vargas D, Monti F, Nseng G, Kleinschmidt I: Increased risks of malaria due to limited residual life of insecticide and outdoor biting versus protection by combined use of nets and indoor residual spraying on Bioko Island. Equatorial Guinea. Malar J 2012, 11:242.

59. Hoek WD: Malaria and agriculture (Special Issue: Malaria and Agriculture). Acta Tropica 2004, 89:95-259.

60. Yadouleton AW, Asidi A, Djouaka RF, Braima J, Agossou CD, Akogbeto MC: Development of vegetable farming: a cause of the emergence of insecticide resistance in populations of Anopheles gambiae in urban areas of Benin. Malar J 2009, 8:103.

61. Van der Berg H, Mutero C, Ichimori K: Guidance on policy-making fo rintegrated vector management. Geneva: World Health Organization; 2012.

62. Sibanda MM, Focke WW, Labuschagne FJ, Moyo L, Nhlapo NS, Maity A, Muiambo H, Massinga P Jr, Crowther NA, Coetzee M, Brindley GW: Degradation of insecticides used for indoor spraying in malaria control and possible solutions. Malar J 2011, 10:307.

63. Merckel RD, Focke WW, Sibanda MM, Massinga P, Crowther NAS: Cointercalation of insecticides with hexadecyl trimethyl ammonium chloride in mozambican bentonite. Mol Crystal Liq Cryst 2012, 555:76-84.

64. Burrows JN, Chibale K, Wells TN: The state of the art in anti-malarial drug discovery and development. Curr Top Med Chem 2011, 11:1226-1254.

65. Burrows JN, Leroy D, Lotharius J, Waterson D: Challenges in antimalarial drug discovery. Future Med Chem 2011, 3:1401-1412

66. Boulton IC, Nwaka S, Bathurst I, Lanzer M, Taramelli D, Vial H, Doerig C, Chibale K, Ward SA: CRIMALDDI: a co-ordinated, rational and integrated effort to set logical priorities in anti-malarial drug discovery initiatives. Malaria Journal 2010, 9:202.

67. MalERA: A research agenda for malaria eradication: drugs. PLoS Med 2011, 8:e1000402.

68. Sanz LM, Crespo B, De-Cozar C, Ding XC, Llergo JL, Burrows JN, Garcia-Bustos JF, Gamo FJ: P. falciparum in vitro killing rates allow to discriminate between different antimalarial mode-of-action. PLoS One 2012, 7:e30949.

69. Coteron JM, Marco M, Esquivias J, Deng X, White KL, White J, Koltun M, El Mazouni F, Kokkonda S, Katneni K, Bhamidipati R, Shackleford DM Angulo-Barturen I, Ferrer SB, Jimenez-Diaz MB, Gamo FJ, Goldsmith EJ, Charman WN, Bathurst I, Floyd D, Matthews D, Burrows JN, Rathod PK, Charman SA, Phillips MA: Structure-guided lead optimization of triazolopyrimidine-ring substituents identifies potent Plasmodium falciparum dihydroorotate dehydrogenase inhibitors with clinical candidate potential. J Med Chem 2011, 54:5540-5561.

70. Bueno JM, Manzano P, Garcia MC, Chicharro J, Puente M, Lorenzo M, Garcia A, Ferrer S, Gomez RM, Fraile MT, Lavandera JL, Fiandor JM, Vidal J, Herreros
E, Gargallo-Viola D: Potent antimalarial 4-pyridones with improved physico-chemical properties. Bioorg Med Chem Lett 2011, 21:5214-5218.

71. Price RN, Tjitra E, Guerra CA, Yeung S, White NJ, Anstey NM: Vivax malaria: neglected and not benign. Am J Trop Med Hyg 2007, 77:79-87.

72. Rossouw CL, Chetty A, Moolman FS, Birkholtz LM, Hoppe H, Mancama DT: Thermo-responsive non-woven scaffolds for "smart" 3D cell culture. Biotechnol Bioeng 2012, 109:2147-2158.

73. Sinden RE, Carter R, Drakeley C, Leroy D: The biology of sexual development of Plasmodium: the design and implementation of transmission-blocking strategies. Malar J 2012, 11:70.

74. Adjalley SH, Johnston GL, Li T, Eastman RT, Ekland EH, Eappen AG, Richman A, Sim BK, Lee MC, Hoffman SL, Fidock DA: Quantitative assessment of Plasmodium falciparum sexual development reveals potent transmissionblocking activity by methylene blue. Proc Natl Acad Sci U S A 2011, 108:E1214-E1223.

75. Delves M, Plouffe D, Scheurer C, Meister S, Wittlin S, Winzeler EA, Sinden RE, Leroy D: The activities of current antimalarial drugs on the life cycle stages of Plasmodium: a comparative study with human and rodent parasites. PLoS Med 2012, 9:e1001169.

doi:10.1186/1475-2875-11-431

Cite this article as: Birkholtz et al: Sustainable malaria control: transdisciplinary approaches for translational applications. Malaria Journal 2012 11:431.

\section{Submit your next manuscript to BioMed Central and take full advantage of:}

- Convenient online submission

- Thorough peer review

- No space constraints or color figure charges

- Immediate publication on acceptance

- Inclusion in PubMed, CAS, Scopus and Google Scholar

- Research which is freely available for redistribution 